\title{
Analysis of the anti-proliferative and the pro-apoptotic efficacy of Syk inhibition in multiple myeloma
}

Ruth-Miriam Koerber ${ }^{\dagger}$, Stefanie Andrea Erika Held ${ }^{\dagger}$, Annkristin Heine, Philipp Kotthoff, Solveig Nora Daecke, Anita Bringmann and Peter Brossart ${ }^{*}$

\begin{abstract}
Background: Multiple myeloma (MM) is a clonal B cell malignancy characterized by proliferation of malignant plasma cells in the bone marrow. Despite high-dose melphalan therapy with autologous stem cell transplantation (ASCT) and the introduction of immunomodulatory drugs like bortezomib or lenalidomide, that have been associated with improved survival, MM is still incurable and new treatment options are needed. In B cell malignancies such as chronic lymphocytic leukaemia (CLL) or diffuse large B cell lymphoma (DLBCL), Syk (spleen tyrosine kinase) inhibitors have shown promising in vitro and first clinical results. In our study, we analyzed the potential of Syk as a target in MM.

Methods: The MM cell lines AMO-1, U266 and RPMI8226 and primary MM cells were treated with the Syk inhibitors BAY61-3606, R406 or Piceatannol and proliferation, migration and apoptosis induction were analyzed. Effects on involved intracellular signaling cascades were determined by Western blotting. Furthermore, we analyzed synergistic and additive effects of Syk inhibitors in combination with established anti-myeloma drugs and experimental inhibitors (e.g. PI-3-Kinase inhibitor NVP-BEZ235).

Results: Incubation of MM cell lines as well as primary MM cells with Syk inhibitors resulted in a reduced proliferation and stromal cell-derived factor-1 alpha (SDF-1 alpha) induced migration that was accompanied by a concentration dependent inhibition of the MAP-Kinase, characterized by reduced phosphorylation of ERK an p38 molecules, and NFkappaB signalling pathways. Furthermore, Syk inhibition induced apoptosis in MM cells in a dose-dependent manner, characterized by reduced expression of pro-caspase 3, increased PARP-1 cleavage and enhanced release of cytochrome c. In addition combined treatment of MM cells with Syk inhibitors and NVP-BEZ235 (dual PI3-kinase/mTOR inhibitor) or MAPK inhibitors (PD98059, SP600125, U0126, SB203580) resulted in increased apoptotic activity of the drugs.
\end{abstract}

Conclusions: Our results show that Syk inhibition might represent a promising new treatment option in MM with an increased efficacy when combined with MAP kinase inhibitors. Furthermore, our study strongly underlines the potency of Syk inhibitors as a potential therapeutic treatment option for MM patients.

Keywords: Spleen tyrosine kinase (Syk), Syk inhibitors, Multiple myeloma, Plasmacell malignancy, Tyrosine kinase, Apoptosis, Signal transduction Bay61-3606, Piceatannol, R406

\section{Background}

Multiple myeloma (MM) is a B cell clonal malignancy characterized by proliferation and accumulation of malignant

\footnotetext{
*Correspondence: Peter.Brossart@ukb.uni-bonn.de

${ }^{\dagger}$ Ruth-Miriam Koerber and Stefanie Andrea Erika Held contributed equally to this study

Medical Clinic III, Department of Hematology and Oncology, University

Hospital Bonn, Sigmund-Freud-Str. 25, 53127 Bonn, Germany
}

plasma cells within the bone marrow (BM) [1]. Several recently introduced therapies such as bortezomib, thalidomide or lenalidomide as well as high dose chemotherapy and autologous stem cell transplantation (ASCT) have improved the prognosis and overall survival of patients with MM. However, MM is still an incurable disease [2,3].

Drug resistance represents one of the major difficulties to overcome in patients with malignant disease which 
often results in failure to eliminate minimal residual tumor cells $[4,5]$. Studies performed in an attempt to determine the factors mediating drug resistance and survival of malignant cells led to the characterization of novel pathways and identification of potential targets for anticancer therapies $[6,7]$. In malignant $B$ cells and plasma cells, the involvement of signalling pathways via Janus kinases $1 / 2$ (JAK1/2) and the signal transducers and activators of transcriptions (STAT) molecules as well as the events mediated by the phosphatidylinositol-3 kinases (PI3-K) and mitogen activated kinases (MAPK) were found to be critical for cell growth, differentiation and survival [8-10].

In addition, emerging evidence suggests that spleen tyrosine kinase (Syk), an intracellular tyrosine kinase, plays a central role upon activation of cells by $\mathrm{B}$ or $\mathrm{T}$ cell receptors (BCR or TCR) as well as by cytokines or adhesion molecules [11-13]. Syk activation is mediated when sarcoma kinases (Src kinases) phosphorylate conserved sequences within receptors containing immune tyrosine activation motifs (ITAMs) $[14,15]$. Once activated, Syk propagates the phosphorylation of further downstream molecules including the PI3-K and MAP-kinase pathways $[16,17]$.

Syk and the zeta-chain-associated protein kinase 70 (ZAP-70) are the only members of the Syk family kinases. Syk was first identified by isolation of tyrosine kinase activity found in the thymus and spleen leading to the cloning of the $72 \mathrm{kDa}$ protein $[18,19]$. Mice with genetically disrupted Syk are deficient in B cell maturation and expansion and die prenatally due to severe bleedings. This indicates that Syk might play a role in angiogenesis and maintaining of vascular integrity [20, 21]. Subsequently, Syk has been found to be involved and play a broad role in hematopoietic cell signalling such as FCeRI receptor in mast cells, FCgRIIA in macrophages and platelets as well as the antigen receptors of $\mathrm{B}$ and $\mathrm{T}$ cells $[22,23]$. In addition, it was demonstrated that Syk is also expressed in fibroblasts, hepatocytes, neuronal cells and vascular endothelium [24]. Syk was shown to function as an oncogene and to be a negative regulator of tumorigenesis in some malignant diseases such as breast cancer, $\mathrm{B}$ and $\mathrm{T}$ cell lymphoma and myelodysplastic syndromes $[25,26]$.

Recently, several reports on preclinical studies demonstrated that Syk inhibition might represent a rational therapeutic target in B cell malignancies such as chronic lymphocytic leukaemia (CLL), diffuse large B-non-Hodgkin lymphoma (DLBCL), follicular and mantle cell lymphoma by interfering with the signalling promoted by the activation via the $\mathrm{BCR}$, cytokines and stromal factors [27-29]. In DLBCL and CLL, first clinical experiences with the clinically available Syk inhibitor R406 provided encouraging and promising results in heavily pre-treated patients [30-32].

In our study we analyzed the effects of the three currently available Syk inhibitors, Piceatannol, Bay-61-3606 and R406 on the viability and functional properties of myeloma cells in order to provide a mechanistic understanding and a rationale for a possible use of these compounds as therapeutic option.

\section{Results}

\section{Syk inhibitors reduce the proliferation and migration} of MM cells

Syk was shown to play an important role in the signal transduction via the $\mathrm{BCR}$, cytokine receptors, integrins and $\mathrm{Fc}$ receptors on normal and malignant B cells. These receptors promote survival and are associated with the induction of proliferation, differentiation and migration. Using Immunoprecipitation, we found that phosphorylated Syk is expressed in the utilized multiple myeloma cell lines AMO-1, U266 and RPMI8226. Furthermore, Syk expression was also detected in primary MM cells of patients with plasma cell leukemia (PCL). In addition, we found that Syk can be downregulated when these myeloma cells were incubated with the inhibitors of Syk phosphorylation, i.e. Bay 61-3606 or Piceatannol and R406 (Fig. 1a, b).

Incubation of MM cell lines with Piceatannol, R406 or Bay 61-3606 led to a concentration dependent decrease of proliferation, as analyzed by ${ }^{3} \mathrm{H}$-thymidine incorporation, and to a reduced stromal cell-derived factor-1 $\alpha$ (SDF-1 $\alpha$ ) induced migration of cells in transwell experiments as depicted in Fig. 2a and b for the AMO-1 cells. Similar results were obtained with other MM cell lines (U266 and RPMI8226).

Additionally, we performed MTT (tetrazolium salt 3-4,5-dimethylthiazol-2yl]-2,5-diphenyl-tetrazolium bromide) cytoxicity assays to ensure that the effects on migration and proliferation induced by Syk inhibitors are not due to cytotoxicity as a mechanism of action. The MTT assays showed no decline in cell viability when incubated with Syk inhibitors. This was proved in three cell lines at three different concentrations. Based on these results, the effects of the various Syk inhibitors on migration and proliferation are not due to cytotoxic effects (see Additional file 1).

In line with these results, we found that treatment of cells with the compounds resulted in a reduced activation of the downstream signalling events characterized by reduced phosphorylation of extracellular signal-regulated kinases 1/2 (ERK1/2) and p38 mitogen-activated protein kinases (Fig. 3a, b) and nuclear localized expression of transcription factors of the nuclear factor kappa-lightchain-enhancer of activated B cells (NF-kB) family RelB 

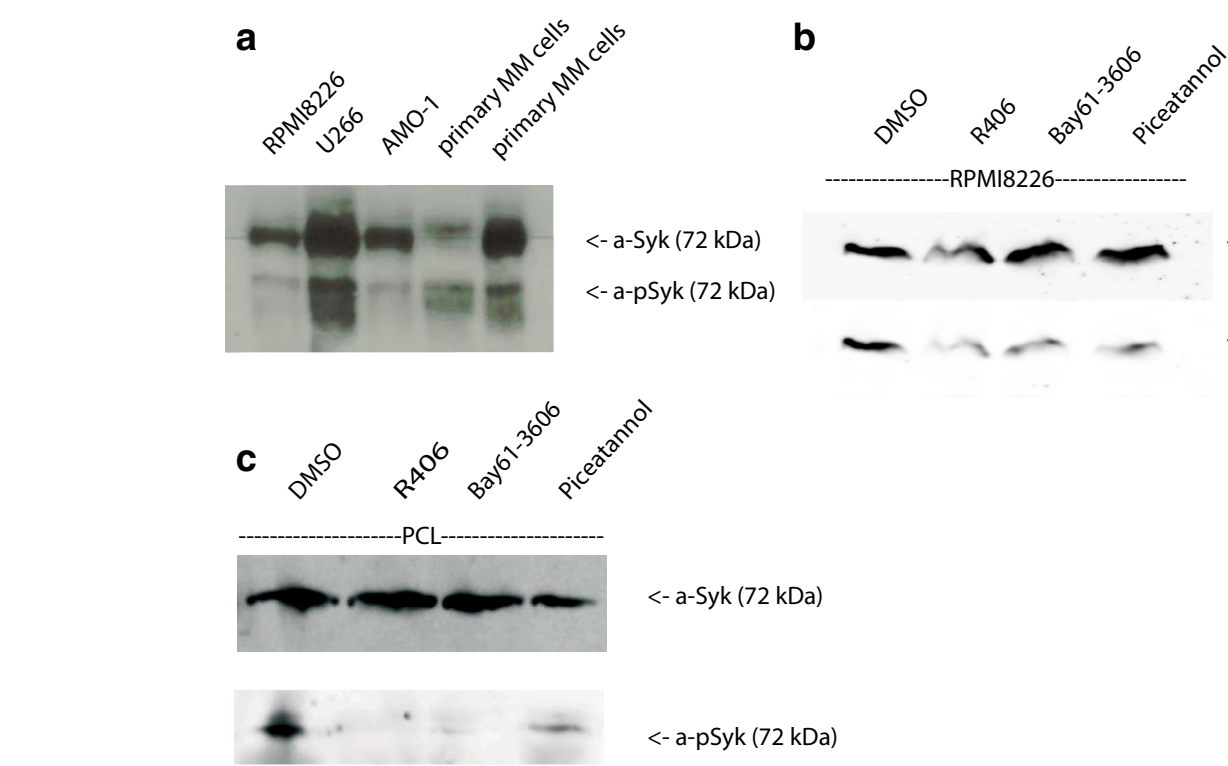

<- a-Syk (72 kDa)
<- a-pSyk (72 kDa)

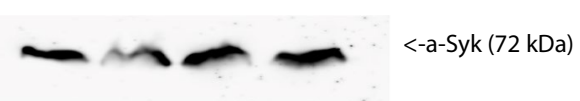

$\longrightarrow>-<-<-p S y k(72 \mathrm{kDa})$

C

a, b Expression of Syk and phosphorylated Syk in different cell lines and patient samples. a Syk was immunoprecipitated from MM cell lines from peripheral blood of myeloma patients with plasma cell leukemia ( $P C L$, purity $>90 \%)$. Displayed is a representative immunoblot of Syk and pSyk in the absence of Syk inhibitors which shows Syk expression in the utilized MM cell lines and PCL-cells. b and c Addition of Syk inhibitors (Piceatannol, R406 and Bay61-3606) reduce the expression of pSyk in MM cell lines and PCL cells. Ponceau S staining was performed to confirm equal amounts of protein.

and RelA (Fig. 3c). Representatively, the results are shown for AMO-1 cell line. However, all used MM cell lines (U266 and RPMI-8226) showed similar results in our experiments. The utilized concentrations of Syk inhibitors were adjusted to reported working concentrations in the literature.

\section{Inhibition of Syk induces apoptosis in MM cells}

In order to analyze the effect of Syk inhibitors on the viability of established MM cell lines, Piceatannol, R406 or Bay61-3606 were added to the cell culture medium and flow cytometric propidium iodide (PI) analysis of DNA fragmentation was performed as described previously [33]. Incubation of cells with the compounds resulted in a concentration dependent cell death induction that was inhibited by the addition of the pan-caspase inhibitor zVAD-FMK. This indicates that caspase activity was indispensable for the observed apoptotic effects (Fig. 4a, b).

Likewise, we wanted to determine the efficacy of the compounds to induce apoptosis in purified MM cells. As shown in Fig. 4c, incubation of primary MM cells from patients with plasma cell leukemia with R406, Piceatannol or Bay61-3606 significantly reduced cell viability.

Caspase- 3 assays and Western Blot analysis revealed that the induction of apoptotic cell death was accompanied by caspase- 3 activation and poly[ADP ribose]polymerase 1 (PARP-1) cleavage (Fig. 5a, b). In addition, an increased release of cytochrome $c$ upon incubation with the compounds indicated that the apoptosis induction in tested MM cells was mediated via the mitochondrial signalling pathway (Fig. 5c). In contrast to previous findings in CLL cells, we could not detect any regulation of the expression of myeloid leukaemia cell differentiation protein MCL-1, the $\mathrm{x}$-linked inhibitor of apoptosis protein xIAP or survivin (also known as BIRC5 or API4) by the used compounds (Fig. 5c).

IL-6 is a major growth and drug-resistance factor for MM cells that activates a cascade of signalling pathways mediating proliferation and anti-apoptotic effects. We therefore analyzed whether IL-6 might interfere with and abrogate the apoptotic effects induced by Syk inhibitors. Preincubation of MM cells with IL-6 had no effect on Piceatannol triggered apoptosis in MM cell lines (Fig. 6). Similarly, preincubation of MM cell lines with TLR ligands (TLR 2, 3, 4, 7/8) had no effect on the action of Syk inhibition (data not shown).

Because bone marrow (BM) microenvironment promotes MM survival and drug resistance, we next determined the apoptosis induction in MM cells in this context. The majority of MM patients expresses the chemokine receptor CXCR4 on neoplastic MM cells which is crucial for myeloma cell migration and homing to the BM microenvironment. Additionally, it supports tumor cell survival and mediates chemotherapy 


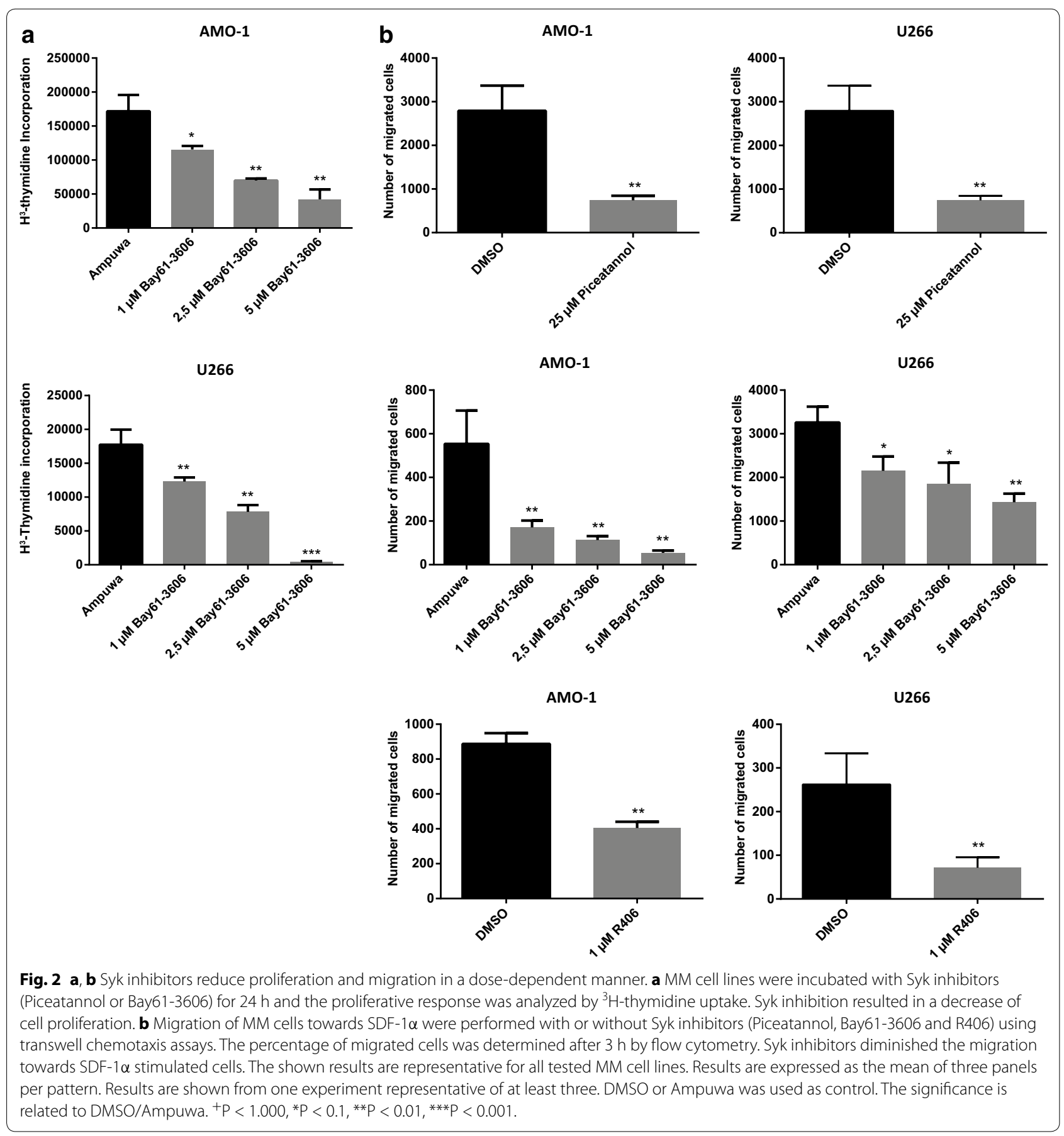

resistance. For contacts of cell-cell and cell to extracellular matrix, a group of cellular adhesion molecules such as CD11a or CD49d are essential, likewise their ligands, i.e. CD102 (ICAM 2). Surface antigens were examined by flow cytometric analysis. Despite reduced migration of cells when treated with Syk inhibitors, we could not detect any effect on the expression of CXCR4, CD49d or CD102 on the cell surface of MM cells (data not shown).

\section{Combined treatment of MM cells with Syk inhibitors}

In the next set of experiments we analyzed possible additive effects of drugs currently used in the treatment of MM with Syk inhibitors. We found no additive effects when Syk inhibitors were used with bortezomib (Fig. 7a). In addition, no additive effects were detected when Syk inhibitors were combined with thalidomide, 


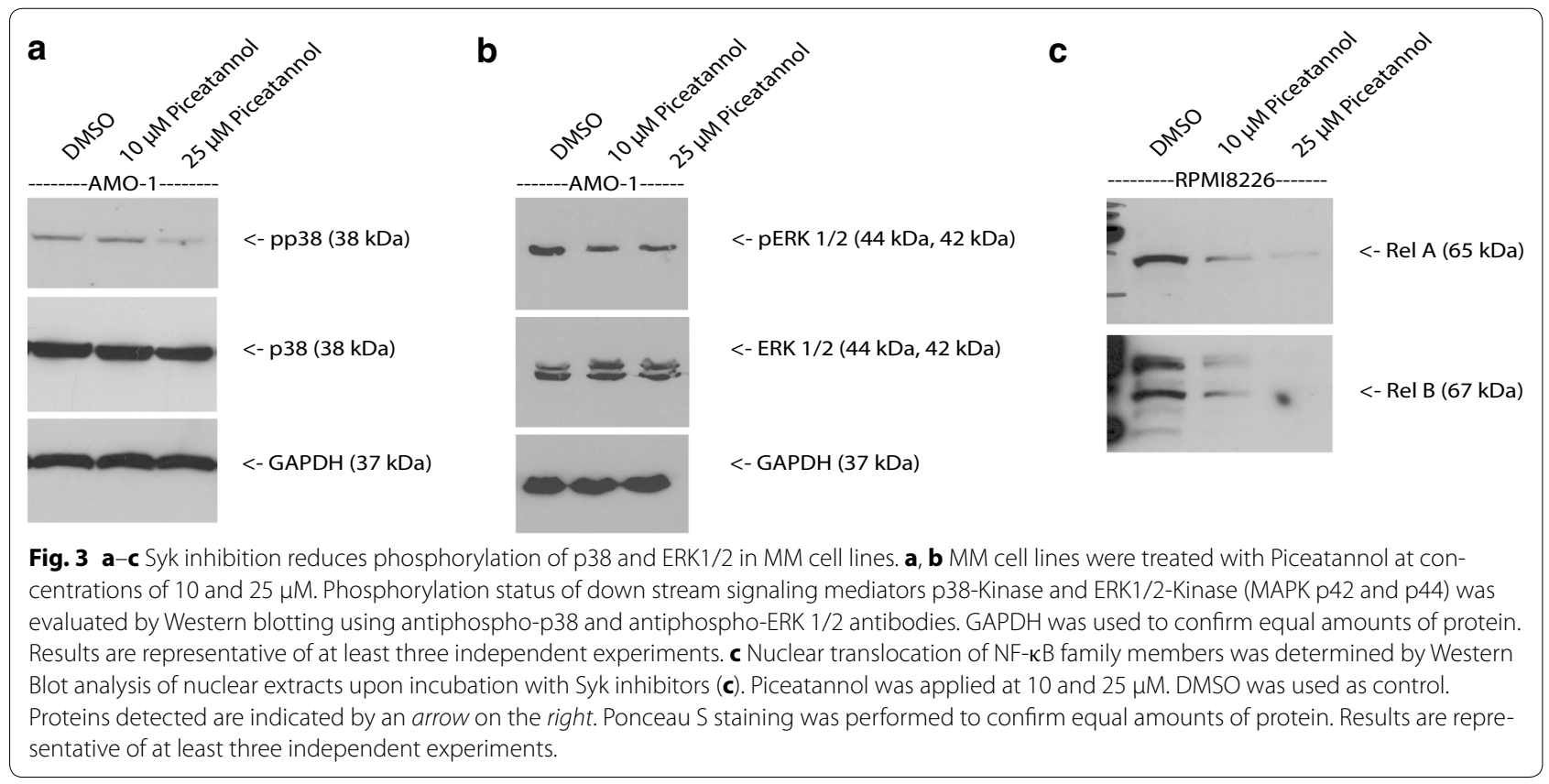

lenalidomide, TRAIL (tumor necrosis factor related apoptosis inducing ligand) or dexamethasone (data not shown).

NVP-BEZ235, an orally available dual PI3 kinase/mTor inhibitor, was recently shown to suppress survival and growth of MM cells in preclinical studies. We found that combined treatment of MM cells with Piceatannol and NVP-BEZ235 significantly increased the cytotoxic effect as compared to each drug alone (Fig. 7a). This was predominantly observed in AMO-1 cells. Significant results could be observed in both cell lines when correlated to Piceatannol, in U266 cells significances correlated to NVP-BEZ235 were not significant, but in AMO-1 they were significantly higher (see Additional file 1).

As mentioned above, MAP-Kinases play a critical role in differentiation, cell growth and survival in MM. Combination of Syk inhibitors with MAP-Kinase inhibitors such as U0126 (a potent, selective inhibitor of MAP2K), PD98059 (an inhibitor of MAP2K/MEK), SP600125 (a selective inhibitor of JNK) and SB203580 (a selective inhibitor of p38 MAPK) resulted in synergistic cytotoxic effects in combination with U0126 (Fig. 7b) and PD98059 (Fig. 7d). Additive effects were observed when combined with SP600125 (a selective inhibitor of JNK, Fig. 7c) or SB203580 (Fig. 7e).

\section{Discussion}

In our study we demonstrate that a proportion of MM cells express Syk and pSyk and Syk inhibitors R406, Piceatannol and Bay61-3606 effectively block proliferation, migration and survival of MM cells. This indicates that Syk inhibition might represent a potential new therapeutic option in the treatment of MM. However, the compounds we used in our experiments are not entirely specific for Syk and do display some lower activity against JAK, Lck, Lyn, STAT3 and STAT 5 as well as against some potential additional, yet to be determined, tyrosine kinases [34, 36, 37].

R406 and BAY61-3606 have previously been reported to inhibit proliferation and to induce apoptosis in nonHodgkin lymphoma (B-NHL) and CLL cells [27, 38]. R406 is currently used in clinical trials and has demonstrated promising activity in patients with B-NHL, ITP and rheumatoid arthritis $[39,40]$. The so far reported side effects of the compound are generally mild and consist primarily of gastrointestinal side effects and neutropenia, which was dose related and rapidly reversible upon dose reduction or discontinuation of treatment [41]. Interestingly, in mice treated with R406, additional immunomodulatory effects including lymphopenia, reduced thymus and spleen weight and decreased cellularity of the BM were observed, which resolved within 2 weeks after stopping the drug application [42].

MM cells express the chemokine receptor CXCR4 and its ligand SDF- $1 \alpha$ controls their $\alpha 4 \beta 1$-mediated adhesion to the vascular adhesion molecule 1 (VCAM1 ), fibronectin and endothelial cells as well as their transendothelial migration and homing in the BM [43, 44]. MM cells are highly dependent on BM microenvironment, where signals provided by cytokines and adhesion molecules promote the survival, proliferation and expansion of MM cells $[45,46]$. In our study we 


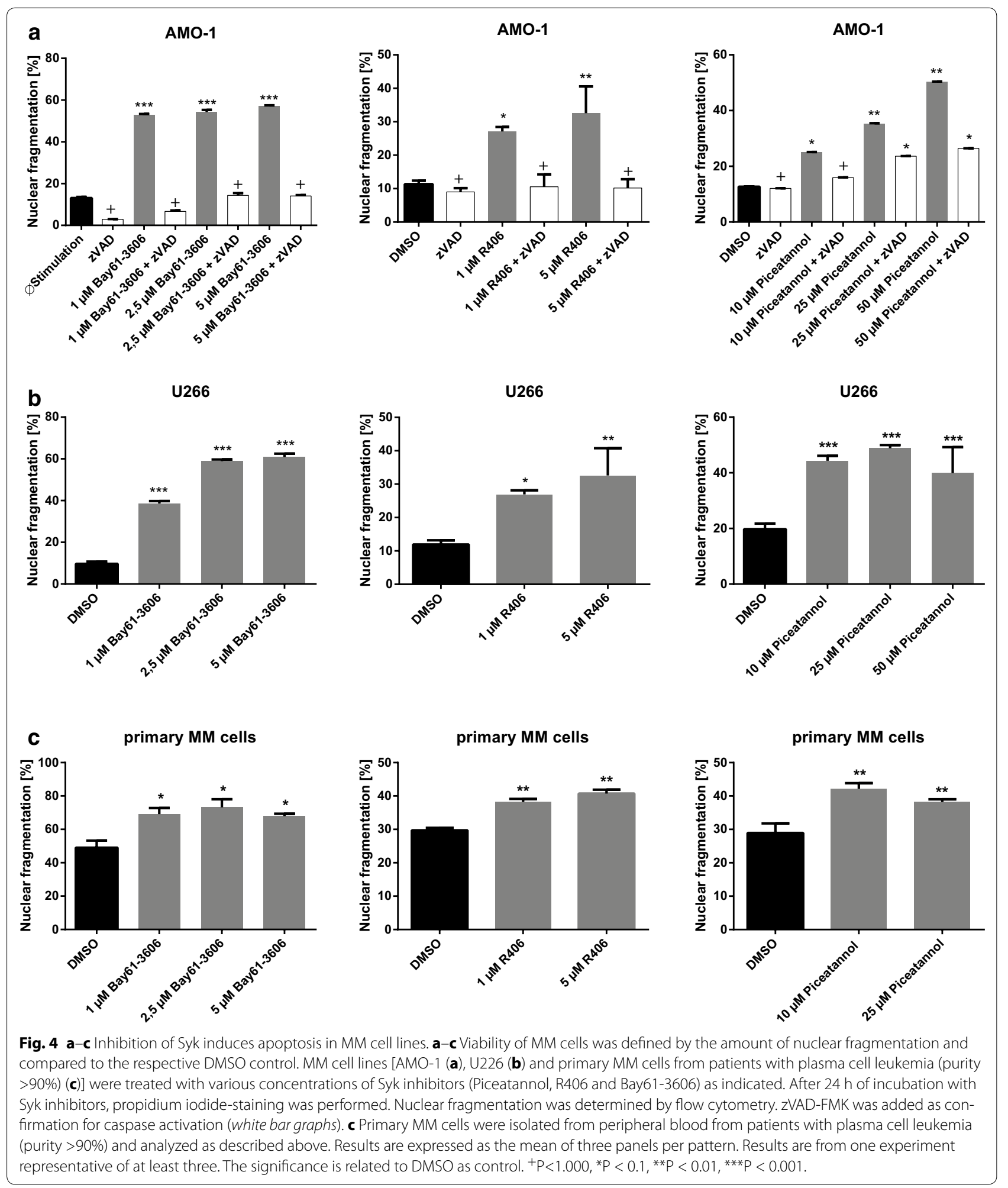

found that treatment of MM cells with Syk inhibitors blocked the SDF- $1 \alpha$ mediated migration of MM cells and abrogated the survival signals provided by IL-6,
TLR ligands or BM stroma. These blocking effects were accompanied by the inhibition of downstream pathways as demonstrated by reduced ERK1/2 and 


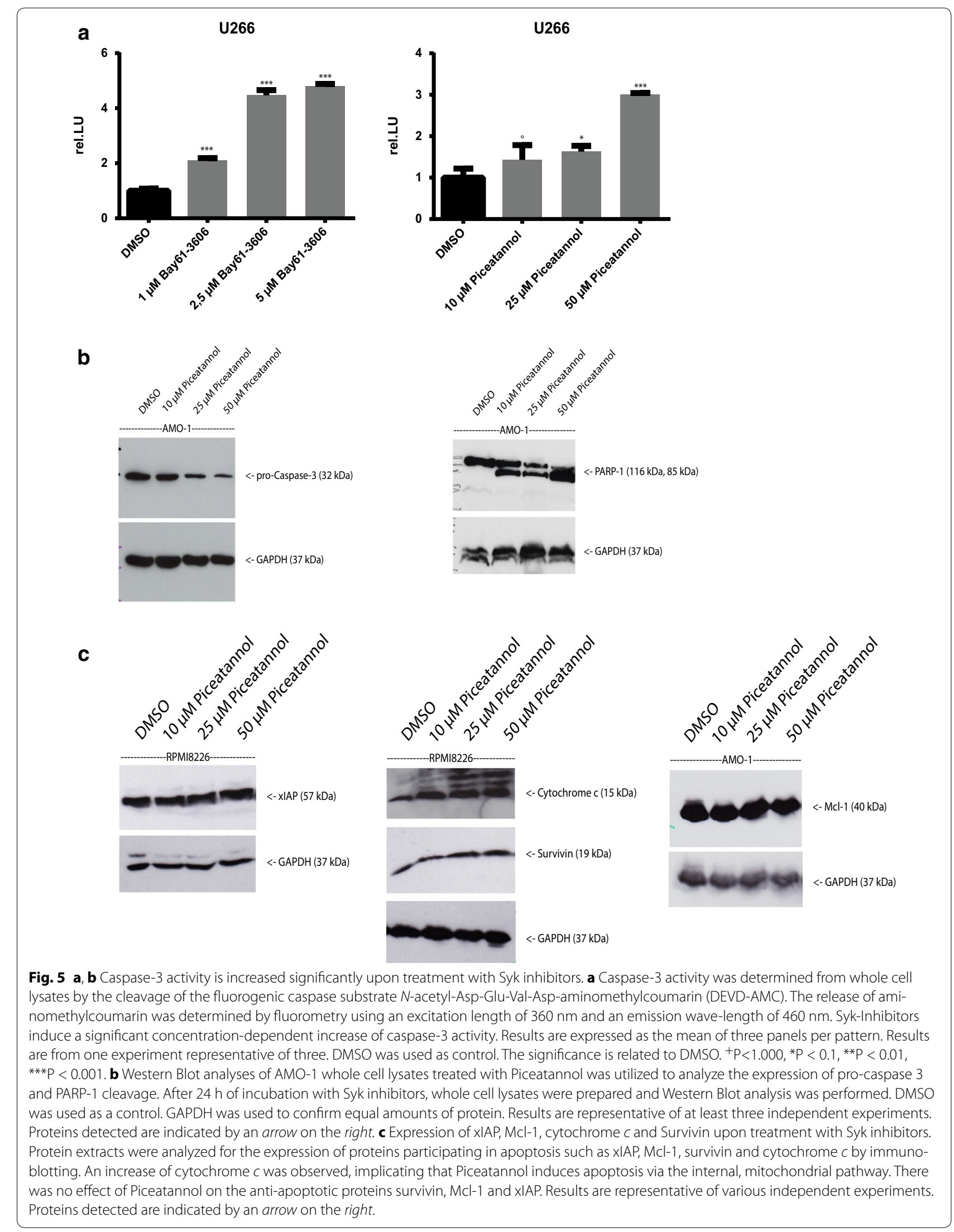


U266

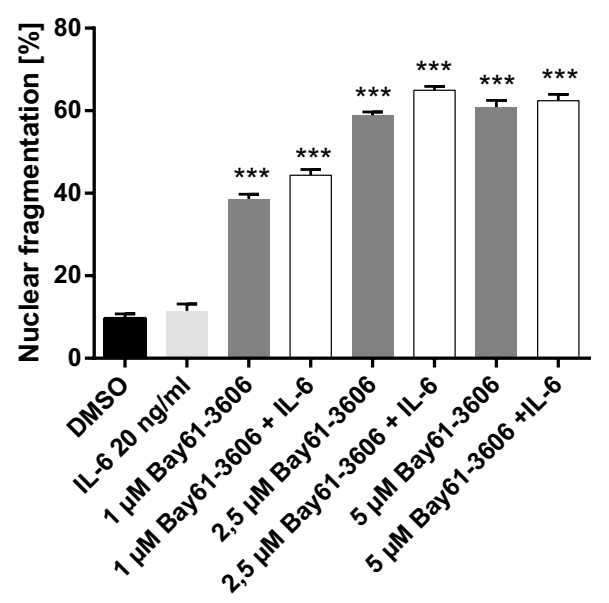

AMO-1

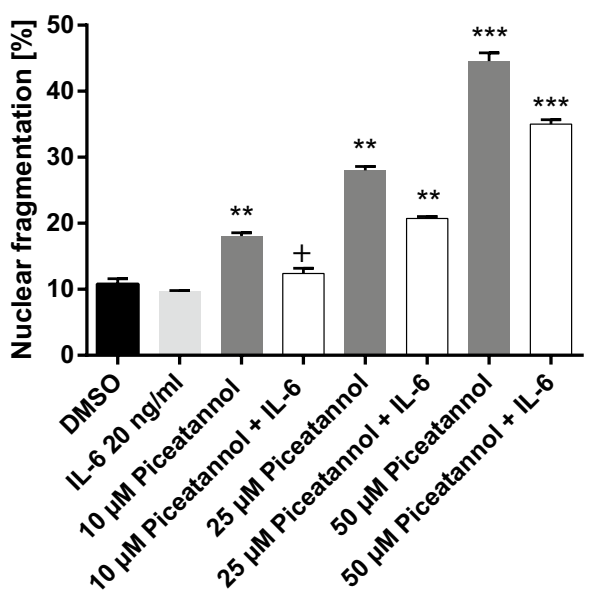

Fig. 6 Efficiacy of Syk inhibition on cell viability is not reduced in the presence of II-6. To determine the impact of IL-6 on the apoptotic effects of Syk inhibitors, MM cells were preincubated with IL-6 and nuclear fragmentation of MM cells treated with Syk inhibitors was measured by flow cytometry. In comparison with Bay61-3606 or Piceatannol alone, a combination with IL-6 did not reduce significantly the number of apoptotic cells. Results are expressed as the mean of three panels per pattern. Results are from one experiment representative of three. DMSO was used as control. The significance is related to DMSO. ${ }^{+} P<1.000,{ }^{*} P<0.1,{ }^{* *} P<0.01,{ }^{* * *} P<0.001$.

p38 phosphorylation and nuclear localized RelB and RelA, indicating that MAP-Kinase and NF- $\kappa$ B signalling pathways are involved in the observed inhibitory effects.

Syk inhibitors efficiently induced apoptosis in established MM cell lines and purified MM cells. This was characterized by an enhanced caspase- 3 activity and PARP-1 cleavage, a known caspase-3 substrate. The induction of cell death was inhibited by the addition of the pan-caspase inhibitor zVAD-FMK, further confirming the critical role of caspases in this setting. In addition, we found that Syk inhibition resulted in enhanced release of cytochrome $c$ indicating that the apoptotic cell death was mediated via the internal, mitochondrial pathway.

Our findings are in line with previous findings in CLL cells [38] where treatment of CLL cells with BAY61-3606 caused caspase- 3 activation, cleavage of PARP-1 and loss of mitochondrial potential. However, in contrast to this report we could not detect any regulation of MCL-1 protein expression in our experiments indicating that the effects and mechanisms induced by the utilized compounds may vary depending on the used cell lines and models.

The introduction of recently developed agents such as the proteasome inhibitor bortezomib or lenalidomide has dramatically improved the prognosis and overall survival in MM patients [47, 48]. Some of the induced effects by these targeted therapies are mediated by interfering with the MAP-Kinase and NF-kB signalling pathways. Therefore, we hypothesized that Syk inhibition might represent a rationale combination partner. While there were no additive effects by bortezomib, the combined treatment of MM cells with MAP-Kinase inhibitors resulted in an increased cytotoxic effect. In addition, we observed that simultaneous exposure to NVP-BEZ235 [49], an orally available dual inhibitor of PI3 kinase/mTor signalling significantly enhanced the efficacy of Syk inhibitors.

\section{Conclusions}

Syk inhibitors already showed promising results in B cell malignancies such as CLL and DLBCL. Our data show successful findings of Syk inhibition in MM. Syk inhibition in $M M$ resulted in decreased proliferation and migration of MM cells. Additionally, Syk inhibition induces apoptosis and is effective in combination with established anti myeloma drugs and experimental new kinase inhibitors, such as a PI3-Kinase inhibitor. In summary, our study provides a mechanistic insight and a rationale for Syk inhibition as a novel therapeutic option for the treatment of MM.

\section{Methods}

\section{Cell culture}

The cells lines AMO-1, U266, RPMI8226 and MM1-S were a kind gift from Helmut Salih from the University Hospital Tuebingen. The cells were cultured in RP10 medium (RPMI 1640 containing GlutaMAX, supplemented with $10 \%$ heat-inactivated fetal calf serum and 100 units/ml penicillin/streptomycin, all from Gibco, 


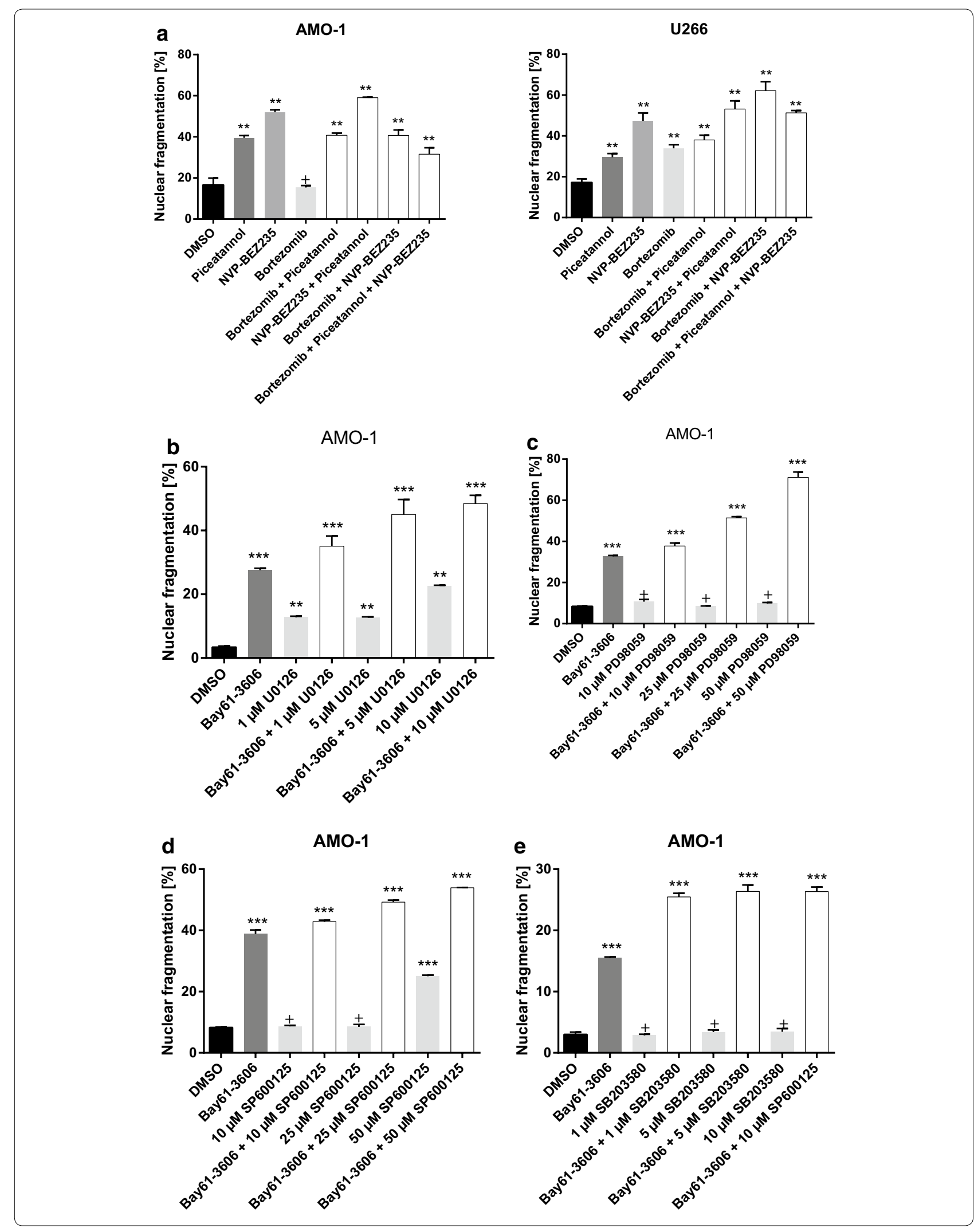


(see figure on previous page.)

Fig. 7 Combined treatment with NVP-BEZ235 or MAPK inhibitors increases induction of apoptosis. a Nuclear fragmentation of MM cells treated with either/and $500 \mathrm{nM}$ NVP-BEZ235, $25 \mu \mathrm{M}$ Piceatannol and $0.5 \mathrm{ng}$ bortezomib. Nuclear fragmentation was determined by the method of Nicoletti and analysed by flow cytometry. In comparison to Piceatannol alone, a combination with the common anti-myeloma agent bortezomib exerts no further increase of nuclear fragmentation. The addition of NVP-BEZ235 (an orally bioavailable dual phosphatidylinositol 3-kinase/mammalian target of rapamycin inhibitor) to Syk inhibitors increased nuclear fragmentation. Statistical analysis showed, that the combination of NVP-BEZ235 and Piceatannol is significantly higher than each drug alone. This works predominantly for AMO-1 cells. Calculational significant results in U266 cells can only be observed when correlated to Piceatannol, but not to NVP-BEZ235 (see Additional file 1). Results are expressed as the mean of three panels per pattern. Results are from one experiment representative of three. DMSO was used as control. The significance is related to DMSO. ${ }^{+} \mathrm{P}<1.000$, ${ }^{*} \mathrm{P}<0.1,{ }^{* * P}<0.01,{ }^{* *} \mathrm{P}<0.001$. b-e Effects of Syk inhibition in combination with MAP-Kinase inhibitors are demonstrated. MM cell lines were incubated with 5 M Bay61-3606 in addition to varying concentrations of U0126 (b), SP600125 (c), PD98059 (d) or SB202190 (e) alone as well as in combination. Combined treatment of Bay61-3606 with U0126 (a potent, selective inhibitor of MAP2K), SP600125 (a selective inhibitor of JNK), or PD98059 (an inhibitor of MAP2K/MEK) and SB203580 (a selective inhibitor of p38 MAPK) results in significant synergistic or additive effects. Results are expressed as the mean of three panels per pattern. Results are from one experiment representative of three. DMSO was used for negative control. The significance is related to DMSO. ${ }^{+} \mathrm{P}<1.000,{ }^{*} \mathrm{P}<0.1,{ }^{* *} \mathrm{P}<0.01,{ }^{* * *} \mathrm{P}<0.001$.

Karlsruhe, Germany) in a humidified atmosphere $\left(37^{\circ} \mathrm{C}, 5 \% \mathrm{CO}_{2}\right)$. Cells were seeded into $75 \mathrm{~cm}^{2}$ flasks at $10^{4} / 10 \mathrm{ml} /$ flask (BD Heidelberg, Deutschland).

After informed consent, blood samples were collected from patients with multiple myeloma hospitalized at the University Hospital Bonn. PBMCs were isolated by Ficoll/Paque (Biochrom, Berlin, Germany) density gradient centrifugation.

Cells were preincubated with zVAD (Bachem Distribution Services $\mathrm{GmbH}$, Weil am Rhein, Germany) for $1 \mathrm{~h}$. Piceatannol, applied at concentrations of 10, 25 and $50 \mu \mathrm{M}$ (Sigma-Aldrich Chemie GmbH, Munich, Germany), R406, applied at concentrations of 1 and $5 \mu \mathrm{M}$, and BAY61-3606, applied at concentrations of 1, 2.5 and $5 \mu \mathrm{M}$, (Sigma-Aldrich Chemie GmbH, Munich, Germany) were added for $24 \mathrm{~h}$. After $24 \mathrm{~h}$, cells were prepared for further experiments.

To analyse possible synergistic effects we tested in addition thalidomide(MP Biochemicals, Solon, Ohio, USA), lenaldomide (Selleck Biochemicals, Houston, TX, USA) TRAIL (R\&D Systems, Minneapolis, MN, USA), NVP-BEZ235 (Novartis Deutschland GmbH, Nürnberg, Germany), Bortezomib (Millenium Pharmaceuticals Limited, Cambridge, MA, USA) and five MAPK Inhibitors (PD98059, SB203580, SP600125, U0126, SB201290 all purchased from Tocris Bioscience, MO, USA).

\section{Preparation of whole cell lysates and nuclear extracts}

For the generation of whole cell lysates, cells were lysed in RIPA buffer containing 1\% Igepal CA-630, 0.5\% NaDeoxycholat, 0.1\% SDS, 2 mM EDTA, $2 \mu \mathrm{g} / \mathrm{ml}$ Aprotinin, $1 \mathrm{mM}$ PMSF. Protein concentration was measured using a bicinchoninic acid (BCA) assay (Pierce, Perbio Science, Bonn, Germany).

Nuclear extracts were prepared as described. In brief, $10^{6}$ cells were incubated in $400 \mu \mathrm{l}$ Buffer A containing $10 \mathrm{mM}$ HEPES $\mathrm{pH}$ 7.9, $10 \mathrm{mM}$ KCL, $0.1 \mathrm{mM}$ EDTA, $0.1 \mathrm{mM}$ EGTA, $1 \mathrm{mM}$ DTT and $0.5 \mathrm{mM}$ PMSF. Cellular membranes were destroyed by addition of $10 \%$ Igepal CA-630 and vigorous vortexing. Nuclei were pelleted by centrifugation and resuspended in buffer $\mathrm{C}$ containing $20 \mathrm{mM}$ HEPES pH 7.9, 0.4 M sodium chloride, $1 \mathrm{mM}$ EDTA, $1 \mathrm{mM}$ EGTA, $1 \mathrm{mM}$ DTT and $0.5 \mathrm{mM}$ PMSF. Nuclear proteins were recovered by centrifugation for 5 min at $20,000 g$.

\section{PAGE and Western blotting}

$20 \mu \mathrm{g}$ of whole cell lysates or nuclear extracts of $1 \times 10^{6}$ cells were separated by SDS-PAGE and subsequently transferred onto nitrocellulose membranes (Whatman, Dassel, Germany). The blots were probed with antibodies against bcl-x, cytochrome $c$, caspase-3, XIAP (all purchased from BD Biosciences, Heidelberg, Germany), ERK 1/2, mcl-1, survivin, RelA, Rel-B (all purchased from Santa Cruz Biotechnology, Inc., Santa Cruz, USA), p38, pp38 (all purchased from Cell Signaling Technology ${ }^{\circledR}$, MA, USA). GAPDH (Santa Cruz Biotechnology, Inc., Santa Cruz, USA) was used as a loading control. Signals were detected using the ECL detection system (GE Healthcare, Munich, Germany).

\section{Immunoprecipitation}

To estimate the expression of the protein tyrosine kinase syk in our multiple myeloma cell lines we performed immunoprecipitation. Cell lysates were assembled as explained above (see preparation of whole cell lysates). For immunoprecipitation Dynabeads ${ }^{\circledR}$ Protein A or Protein G from Invitrogen (Life Technologies GmbH, Darmstadt, Germany) were used. The primary antibodies ( $3 \mu \mathrm{l} /$ sample) were pooled to $50 \mu$ l Dynabeads ${ }^{\circledR}$ Protein A and $\mathrm{G}$. To isolate the generated complexes we washed (each with $200 \mu \mathrm{l}$ AB Binding und Wasch Puffer) the solution and the suspension was passed by two magnets where the magnetic beads were reversibly trapped in the magnetic field and formed a compact dense plug. 
To avoid co-elution of the antibody we cross linked the primary antibody to Dynabeads ${ }^{\circledR}$. DSS was eluted in DMSO and a working solution consisting of $20 \times$ Coupling Buffer $(2.5 \mu \mathrm{l}), 2.5 \mathrm{mM}$ DSS and ultrapure water $(38.5 \mu \mathrm{l})$ was established. The Dynabeads ${ }^{\circledR}$-antibody complex was resuspended in $50 \mu \mathrm{l}$ working solution and incubated for 30-60 $\mathrm{min}$ in this solution.

Subsequent the Beads were resuspended with the whole cell lysates (100-500 $\mu$ g protein). The Dynabeads ${ }^{\circledR}$ antibody-antigen-complex was then incubated for $1 \mathrm{~h}$, followed by a couple of steps of washing $(3 \times 200 \mu$ Wash Buffer, $1 \times 100 \mu$ l Wash Buffer), magnetic field exposition and resuspending in $20 \mu \mathrm{l}$ Elution buffer. Afterwards the pure precipitate was eluted from the beads of the supernatant and then analyzed by western blotting (explanation see PAGE and Western Blotting). The blots were probed with an antibody against p-syk (purchased from Santa Cruz Biotechnology, Inc., Santa Cruz, USA).

\section{Measurement of apoptosis}

Apoptosis was measured by the method of Nicoletti [33]. $1 \times 10^{5}$ cells were incubated in a hypotonic buffer containing $1 \%$ sodium citrate, $0.1 \%$ Triton X-100, $50 \mu \mathrm{g}$ of propidium iodide per $\mathrm{ml}$ and subsequently measured by flow cytometry on a Cytomics FC 500 (Beckmann Coulter, Krefeld, Germany) using CXPAnalysis software. The hypodiploid cells to the left of the $2 \mathrm{~N}$ peak were considered as apoptotic.

\section{Fluorimetric assay of caspase- 3 activity}

Caspase activity was determined from cytosolic extracts, by the cleavage of the fluorogenic caspase substrate $N$-acetyl-Asp-Glu-Val-Asp-aminomethylcoumarin (DEVD-AMC, Bachem, Heidelberg, Germany). In brief, for fluorimetric assay of caspase activity, cytosolic cell extracts were prepared by lysing cells in a buffer containing 0.5\% NP-40, $20 \mathrm{mM}$ HEPES pH 7.4, $84 \mathrm{mM} \mathrm{KCl}, 10 \mathrm{mM}$ $\mathrm{MgCl}_{2}, 0.2 \mathrm{mM}$ EDTA, $0.2 \mathrm{mM}$ EGTA, $1 \mathrm{mM}$ DTT, $5 \mu \mathrm{g} /$ $\mathrm{ml}$ aprotinin, $1 \mu \mathrm{g} / \mathrm{ml}$ leupeptin, $1 \mu \mathrm{g} / \mathrm{ml}$ pepstatin and $1 \mathrm{mM}$ PMSF. Cell lysates were incubated with $50 \mathrm{mM}$ DEVD-AMC in $200 \mu \mathrm{l}$ buffer containing $37.5 \mathrm{mM}$ HEPES $\mathrm{pH}$ 7.3, $75 \mathrm{mM} \mathrm{NaCl}, 7.5 \%$ sucrose, 0,075\% CHAPS and $10 \mathrm{mM}$ DTT. The release of aminomethylcoumarin was determined by fluorometry using an excitation length of $360 \mathrm{~nm}$ and an emission wave-length of $460 \mathrm{~nm}$.

\section{Phenotyping of MM cells}

Cells were treated as mentioned above. After incubation staining for fluorescence-activating cell sorting (FACS) followed. $5 \times 10^{5}$ cells/tube were incubated with $10 \mu \mathrm{l}$ anti-CD49d PE (purchased from BD Biosciences Europe, Erembodegem, Belgium), CD102 PE (purchased from BD Biosciences Europe, Erembodegem, Belgium) or CXCR4
PE (purchased from Beckman Coulter GmbH, Krefeld, Germany) and $10 \mu \mathrm{l}$ anti-mouse IgG1, $\kappa \mathrm{PE}$ for $30 \mathrm{~min}$ at $18-22^{\circ} \mathrm{C}$ in the dark. When examined the next day, cells were fixed in $250 \mu \mathrm{l}$ FACS-Buffer and $250 \mu \mathrm{l} 2 \%$ formaldehyde and then analyzed by flow cytometry.

\section{Proliferation assay}

Multiple myeloma cells were seeded into 96-well microtiter plates (Greiner Bio-One $\mathrm{GmbH}$, Frickenhausen, Germany) at $10^{6}, 10^{5}$ or $10^{4}$ cells/well and incubated for $24 \mathrm{~h}$ at $37^{\circ} \mathrm{C}, 5 \% \mathrm{CO}_{2}$. The assay was performed in fourfold replicates. Cells were pulsed with ${ }^{3} \mathrm{H}$-thymidine (Hartmann Analytic, Braunschweig, Germany) and incubated for another $16 \mathrm{~h}$ at $37^{\circ} \mathrm{C}, 5 \% \mathrm{CO}_{2}$. Cells were harvested then using a Filter Mate Harvester (Perkin Elmer, Waltham, USA) and uptake of ${ }^{3} \mathrm{H}$-thymidine was measured by a Microbeta TriLux (Perkin Elmer).

\section{Migration assay}

Cells were seeded into transwell chambers $(8 \mu \mathrm{m}, \mathrm{BD})$ in 24-well plates (BD) and migration was induced through SDF- $1 \alpha$ (Biovision, Mountain View, CA, USA).

After $3 \mathrm{~h}$ migrated multiple myeloma cells were analyzed by counting gated cells for a time interval of $60 \mathrm{~s}$ on a Cytomics FC 500 (Beckmann Coulter).

\section{TACS $^{\circledR}$-MTT cell proliferation assay}

Measurement of cell viability and proliferation were performed with TACS ${ }^{\circledR}$-MTT assay to quantify the cell population's response to Syk inhibitors. The yellow tetrazolium salt 3-4,5-dimethylthiazol-2yl]-2,5-diphenyltetrazolium bromide (MTT) is reduced by metabolic active cells and can then be quantitated by spectroscopic means. Measurement of proliferation and cell viability can be determined over the metabolic events that lead to apoptosis or necrosis.

Cells were cultured and treated with Syk Inhibitors as mentioned above and then plated in the wells. After adding the MTT agent, cells were incubated in the incubator until a purple dye was visible. In the next step Detergent Reagent was added and then the flat-bottomed 96-well plates were read after $2 \mathrm{~h}$ with the microplate reader at $570 \mathrm{~nm}$. The average value was determined from triplicate reading.

\section{Syk inhibitors}

Piceatannol (Sigma-Aldrich Chemie GmbH, Munich, Germany), a plant secondary product (3,4,3,5-tetrahydroxy-trans-stilbene), was identified as a tyrosine kinase inhibitor in thymocytes that also displays some activity against Lyn and STATs. The used concentrations were adjusted to reported working concentrations in literature. BAY61-3606 (Sigma-Aldrich Chemie GmbH, Munich, 
Germany), (orally available 2-(7-(3,4-dimethoxyphenyl)imidazol(1,2-c)pyrimidin-5-ylamino)nicotinamide dihydrochloride), is a specific Syk inhibitor that acts as an ATP competitor blocking its catalytic activity and was shown to inhibit antigen-induced airway inflammation in rodents [34]. The used concentrations were adjusted to reported working concentrations in literature.

R406 is an adenosine triphosphate competitive, small molecule that was developed as a specific Syk inhibitor by Rigel Pharmaceuticals (San Francisco, CA, USA) with lower activity against FMS-like tyrosine kinase 3 (Flt3), JAK 1/2 and lymphocyte-specific protein tyrosine kinase (Lck) and is currently used in clinical trials for rheumatoid arthritis, idiopathic thrombocytopenic purpura (ITP), B-CLL and DLBCL. The used concentrations of this compound in our experiments represent serum levels obtained in treated patients. In volunteers and patients, plasma levels after a single dose of R406 between 1 and $5 \mu \mathrm{g} / \mathrm{ml}$ were reported [35].

\section{Statistics}

Variance analysis was performed using SPSS 17.0 of SPSS Inc. Evaluation of synergistic effects was performed using SAS 9.2 from SAS Institute Inc.

\section{Additional file}

Additional file 1: Effects of Syk-inhibitors are not due to cytotoxic effects. To quantify the cell population's response to Syk inhibitors we performed measurement of cell viability and proliferation with TACS ${ }_{-}^{{ }_{-}}$ MTT. MM cell lines were incubated with Syk inhibitors (Piceatannol, R406 or Bay61-3606) and active cells were quantitated by spectroscopic means. Furthermore $\mathrm{ZVAD}$, a pan-caspase inhibitor, and triton $2 \%$, as positive control, were added. Measurement of proliferation and cell viability within this MTT-assay can be determined over the metabolic events that lead to apoptosis or necrosis. The MTT assays showed no decline in cell viability when incubated with Syk inhibitors. The significance is related to DMSO/ Ampuwa. ${ }^{+} P<1.000,{ }^{*} P<0.1,{ }^{* *} P<0.01,{ }^{* * *} P<0.001$

\section{Authors' contributions}

RMK carried out the proliferation assays, immunoassays, western blots, caspase assays and statistics and participated in the sequence alignment and drafted parts the manuscript. SND carried out the proliferation and migration assays, immunoassays, western blots. AH participated in the sequence alignment. SAEH and AB participated in the design of the study and wrote parts of the manuscript. PB conceived of the study, and participated in its design and coordination and helped to draft the manuscript. All authors read and approved the final manuscript.

\section{Acknowledgements}

We thank Anika Beckers and Kati Riethausen for their excellent technical assistance. This work was supported by grants from Deutsche Forschungsgemeinschaft (DFG) (PB), Deutsche Krebshilfe (PB), BONFOR Forschungsförderung (AH). Parts of this work were presented on the annual meeting of the American Society of hematology (ASH) as a poster under a different title.

\section{Compliance with ethical guidelines}

\section{Competing interests}

The authors declare that they have no competing interests.
Received: 1 July 2015 Accepted: 20 July 2015

Published online: 05 August 2015

\section{References}

1. Rajkumar SV. Multiple myeloma. Curr Probl Cancer. 2009;33(1):7-64.

2. Laubach JP, Mahindra A, Mitsiades CS, Schlossman RL, Munshi NC, Ghobrial IM, et al. The use of novel agents in the treatment of relapsed and refractory multiple myeloma. Leukemia. 2009;23(12):2222-32.

3. Mahindra A, Cirstea D, Raje N. Novel therapeutic targets for multiple myeloma. Future Oncol. 2010;6(3):407-18.

4. Siegel DS. Relapsed/refractory multiple myeloma: defining refractory disease and identifying strategies to overcome resistance. Semin Hematol. 2012:49(Suppl 1):S3-15.

5. Podar K, Chauhan D, Anderson KC. Bone marrow microenvironment and the identification of new targets for myeloma therapy. Leukemia. 2009;23(1):10-24.

6. Efremov DG, Laurenti L. The Syk kinase as a therapeutic target in leukemia and lymphoma. Expert Opin Investig Drugs. 2011;20(5):623-36.

7. Gururajan M, Jennings CD, Bondada S. Cutting edge: constitutive B cell receptor signalling is critical for basal growth of B lymphoma. J Immunol. 2006;176:5715-9.

8. Uckun FM, Qazi S, Ma H, Tuel-Ahlgren L, Ozer Z. STAT3 is a substrate of SYK tyrosine kinase in B-lineage leukemia/lymphoma cells exposed to oxidative stress. Proc Natl Acad Sci USA. 2010;107(7):2902-7.

9. Hideshima T, Bergsagel PL, KuehI WM, Anderson KC. Advances in biology of multiple myeloma: clinical applications. Blood. 2004;104(3):607-18.

10. Dong C, Davis RJ, Flavell RA. MAP kinases in the immune response. Ann Rev Immunol. 2002;20:55-72.

11. Mocsai A, Ruland J, Tybulewicz VL. The SYK tyrosine kinase: a crucial player in diverse biological functions. Nat Rev Immunol. 2010;10(6):387-402.

12. Kazerounian S, Duquette M, Reyes MA, Lawler JT, Song K, Perruzzi $C$, et al. Priming of the vascular endothelial growth factor signalling pathway by thrombospondin-1, CD36, and spleen tyrosine kinase. Blood. 2011;117(17):4658-66.

13. Park $H$, Cox D. Syk regulates multiple signaling pathways leading to CX3CL1 chemotaxis in macrophages. J Biol Chem. 2011;286(17):14762-9.

14. Geahlen RL. Syk and pTyr'd: signaling through the B cell antigen receptor. Biochim Biophys Acta. 2009;1793(7):1115-27.

15. Turner M, Schweighoffer E, Colucci F, Di Santo JP, Tybulewicz VL. Tyrosine kinase SYK: essential functions for immunoreceptor signalling. Immunol Today. 2000;21:148-54.

16. Robinson MJ, Cobb MH. Mitogen-activated protein kinase pathways. Curr Opin Cell Biol. 1997;9(2):180-6.

17. Wang LD, Clark MR. B cell antigen-receptor signalling in lymphocyte development. Immunology. 2003;110(4):411-20.

18. Deindl S, Kadlecek TA, Brdicka T, Cao X, Weiss A, Kuriyan J. Structural basis for the inhibition of tyrosine kinase activity of ZAP-70. Cell. 2007; 129:735-46.

19. Sada K, Takano T, Yanagi S, Yamamura H. Structure and function of Syk protein-tyrosine kinase. J Biochem. 2001;130(2):177-86.

20. Turner M, Mee PJ, Costello PS, Williams O, Price AA, Duddy LP, et al. Perinatal lethality and blocked $B$ cell development in mice lacking the tyrosine kinase Syk. Nature. 1995;378:298-302.

21. Cheng AM, Rowley B, Pao W, Hayday A, Bolen JB, Pawson T. Syk tyrosine kinase required for mouse viability and $B$ cell development. Nature. 1995;378:303-6.

22. Kiener PA, Rankin BM, Burkhardt AL, Schieven GL, Gilliland LK, Rowley RB, et al. Cross-linking of Fc gamma receptor I (Fc gamma RI) and receptor II (Fc gamma RII) on monocytic cells activates a signal transduction pathway common to both Fc receptors that involves the stimulation of p72 Syk protein tyrosine kinase. J Biol Chem. 1993;268(32):24442-8.

23. Oliver JM, Burg DL, Wilson BS, McLaughlin JL, Geahlen RL. Inhibition of mast cell Fc epsilon R1-mediated signaling and effector function by the Syk-selective inhibitor, piceatannol. J Biol Chem. 1994;269(47):29697-703.

24. Larive RM, Urbach S, Poncet J, Jouin P, Mascre G, Sahuquet A, et al. Phosphoproteomic analysis of Syk kinase signaling in human cancer cells reveals its role in cell-cell adhesion. Oncogene. 2009;28(24):2337-47. 
25. Coopman PJ, Do MT, Barth M, Bowden ET, Hayes AJ, Basyuk E, et al. The Syk tyrosine kinase suppresses malignant growth of human breast cancer cells. Nature. 2000;406:742-7.

26. Coopman PJ, Müller SC. The Syk tyrosine kinase: a new negative regulator in tumor growth and progression. Cancer Lett. 2006;241:159-73.

27. Young RM, Hardy IR, Clarke RL, Lundy N, Pine P, Turner BC, et al. Mouse models of non-Hodgkin lymphoma reveal Syk as an important therapeutic target. Blood. 2009;113(11):2508-16.

28. Baudot AD, Jeandel PY, Mouska X, Maurer U, Tartare-Deckert S, Raynaud $\mathrm{SD}$, et al. The tyrosine kinase Syk regulates the survival of chronic lymphocytic leukemia B cells through PKCdelta and proteasome-dependent regulation of Mcl-1 expression. Oncogene. 2009;28(37):3261-73.

29. Buchner M, Baer C, Prinz G, Dierks C, Burger M, Zenz T, et al. Spleen tyrosine kinase inhibition prevents chemokine- and integrin-mediated stromal protective effects in chronic lymphocytic leukemia. Blood. 2010;115(22):4497-506.

30. Davis RE, Ngo VN, Lenz G, Tolar P, Young RM, Romesser PB, et al. Chronic active B-cell-receptor signalling in diffuse large B-cell lymphoma. Nature. 2010;463(7277):88-92.

31. Buchner M, Fuchs S, Prinz G, Pfeifer D, Bartholome K, Burger M, et al. Spleen tyrosine kinase is overexpressed and represents a potential therapeutic target in chronic lymphocytic leukemia. Cancer Res. 2009;69(13):5424-32.

32. Chen L, Monti S, Juszczynski P, Daley J, Chen W, Witzig TE, et al. SYKdependent tonic $B$ cell receptor signaling is a rational treatment target in diffuse large B cell lymphoma. Blood. 2008;111(4):2230-7.

33. Riccardi C, Nicoletti I. Analysis of apoptosis by propidium iodide staining and flow cytometry. Nat Protoc. 2006;1(3):1458-61.

34. Yamamoto N, Takeshita K, Shichijo M, Kokubo T, Sato M, Nakashima $K$, et al. The orally available spleen tyrosine kinase inhibitor 2-[7-(3,4-dimethoxyphenyl)-imidazo[1,2-c]pyrimidin-5-ylamino]nicotinamide dihydrochloride (BAY 61-3606) blocks antigen-induced airway inflammation in rodents. J Pharmacol Exp Ther. 2003;306(3):1174-81.

35. Baluom M, Samara E, Grossbard EB, Lau DT. Fostamatinib, a Syk-kinase inhibitor, does not affect methotrexate pharmacokinetics in patients with rheumatoid arthritis. J Clin Pharmacol. 2011;51(9):1310-8.

36. Ashikawa K, Majumdar S, Banerjee S, Bharti AC, Shishodia S, Aggarwal BB. Piceatannol inhibits TNF-induced NF-kappaB activation and NF-kappaBmediated gene expression through suppression of IkappaBalpha kinase and p65 phosphorylation. J Immunol. 2002;169(11):6490-7.

37. Wieder T, Prokop A, Bagci B, Essmann F, Bernicke D, Schulze-Osthoff $K$, et al. Piceatannol, a hydroxylated analog of the chemopreventive agent resveratrol, is a potent inducer of apoptosis in the lymphoma cell line BJAB and in primary, leukemic lymphoblasts. Leukemia. 2001;15(11):1735-42.
38. Quiroga MP, Balakrishnan K, Kurtova AV, Sivina M, Keating MJ, Wierda WG, et al. B cell antigen receptor signaling enhances chronic lymphocytic leukemia cell migration and survival: specific targeting with a novel spleen tyrosine kinase inhibitor, R406. Blood. 2009;114(5):1029-37.

39. Ghosh D, Tsokos GC. Spleen tyrosine kinase: an Src family of non-receptor kinase has multiple functions and represents a valuable therapeutic target in the treatment of autoimmune and inflammatory diseases. Autoimmunity. 2010;43(1):48-55.

40. Weinblatt ME, Kavanaugh A, Genovese MC, Musser TK, Grossbard EB, Magilavy DB. An oral spleen tyrosine kinase (Syk) inhibitor for rheumatoid arthritis. N Engl J Med. 2010;363(14):1303-12

41. Friedberg JW, Sharman J, Sweetenham J, Johnston PB, Vose JM, Lacasce A, et al. Inhibition of Syk with fostamatinib disodium has significant clinical activity in non-Hodgkin lymphoma and chronic lymphocytic leukemia. Blood. 2010;115(13):2578-85.

42. Zhu Y, Herlaar E, Masuda ES, Burleson GR, Nelson AJ, Grossbard EB, et al. Immunotoxicity assessment for the novel Spleen tyrosine kinase inhibitor R406. Toxicol Appl Pharmacol. 2007;221(3):268-77.

43. Hauser AE, Debes GF, Arce S, Cassese G, Hamann A, Radbruch A, et al. Chemotactic responsiveness toward ligands for CXCR3 and CXCR4 is regulated on plasma blasts during the time course of a memory immune response. J Immunol. 2002;169(3):1277-82.

44. Moller C, Stromberg T, Juremalm M, Nilsson K, Nilsson G. Expression and function of chemokine receptors in human multiple myeloma. Leukemia. 2003;17(1):203-10.

45. Hideshima T, Mitsiades C, Tonon G, Richardson PG, Anderson KC. Understanding multiple myeloma pathogenesis in the bone marrow to identify new therapeutic targets. Nat Rev Cancer. 2007;7(8):585-98.

46. Podar K, Tai YT, Davies FE, Lentzsch S, Sattler M, Hideshima T, et al. Vascular endothelial growth factor triggers signaling cascades mediating multiple myeloma cell growth and migration. Blood. 2001;98(2):428-35.

47. Wang A, Duan Q, Liu X, Ding K, Han Y, Zhu W, et al. (Bortezomib plus lenalidomide/thalidomide)- vs. (bortezomib or lenalidomide/thalidomide)containing regimens as induction therapy in newly diagnosed multiple myeloma: a meta-analysis of randomized controlled trials. Ann Hematol. 2012;91(11):1779-84.

48. Pan B, Lentzsch S. The application and biology of immunomodulatory drugs (IMiDs) in cancer. Pharmacol Ther. 2012;136(1):56-68.

49. McMillin DW, Ooi M, Delmore J, Negri J, Hayden P, Mitsiades N, et al. Antimyeloma activity of the orally bioavailable dual phosphatidylinositol 3-kinase/mammalian target of rapamycin inhibitor NVP-BEZ235. Cancer Res. 2009;69(14):5835-42.

\section{Submit your next manuscript to BioMed Central and take full advantage of:}

- Convenient online submission

- Thorough peer review

- No space constraints or color figure charges

- Immediate publication on acceptance

- Inclusion in PubMed, CAS, Scopus and Google Scholar

- Research which is freely available for redistribution

Submit your manuscript at 